\title{
Impactos da terceirização em empregados efetivos: Um caso na construção de edificações
}

Impacts of outsourcing on effective employees: A case in building construction

Los impactos de la subcontratación en los empleados fijos: Un caso de la construcción de edificios

\author{
Lívia de Oliveira BORGES ${ }^{1}$ \\ Georgina Maria Véras MOTTA \\ Bárbara Katherine Faris BIONDINI \\ Lívia Moreno LIMA \\ Paloma Alonso ESCARCE \\ Universidade Federal de Minas Gerais, Belo Horizonte, MG, Brasil
}

ResumO Em um contexto de expansão da terceirização na economia, pesquisamos com o objetivo de comparar a percepção sobre aspectos das condições de trabalho e a atribuição de significados ao trabalho por empregados efetivos em uma empresa de construção de edificações com adoção extensiva de terceirização (EA) com os de outra empresa (EB) que com menor adoção de terceirização (EB). Na pesquisa de campo, aplicamos, junto a 187 operários, partes do Inventário do Significado do Trabalho e do Questionário de Condições de Trabalho, e entrevistamos 16 operários e gestores para diferenciar os contextos organizacionais. Encontramos, entre outros aspectos, que os empregados da EB percebem mais Riscos de Acidentes de Trabalho e mais Autonomia (jornada de trabalho e escolha de colegas), enquanto os da EA tendem a valorizar mais a Expressão de Respeito e o Acolhimento e a atribuir mais fortemente significados de Ser Reconhecido e Ser Retribuído Equitativamente. Concluímos que o estilo gerencial provavelmente impacta mais tais conteúdos simbólicos dos operários efetivos do que a extensão da terceirização.

Palavras-chave:

Terceirização; empresas líderes; pesquisa comparativa; edificações.

Abstract In the context in which outsourcing has expanded in the economy, we conducted research aiming to compare the perception of aspects of working conditions, and the attribution of meaning to work, between effective employees in a building construction company (cA), with extensive adoption of outsourcing, and others those in another company $(\mathrm{cB})$, with less adoption of outsourcing. In the field research, we applied parts of the Meaning of Work Inventory and the Questionnaire on Working Conditions to 187 workers, and interviewed 16 workers and managers to differentiate the organizational contexts. We found, among other aspects, that the employees of $\mathrm{cB}$ perceive more Risk of Work Accidents and more Autonomy (working hours and choice of colleagues), while the employees of $\mathrm{cA}$ tend to value more the Expression of Respect and Acceptance and attribute stronger meanings to Being Recognized and Being Equitably Rewarded. We conclude that managerial style probably has more impact on such symbolic content from effective workers than does the extent of outsourcing. Keywords:

Outsourcing; leading firms; comparative research; buildings.

Resumen

En un contexto en que la expansión de la subcontratación en la economía, investigamos con el objetivo de cotejar la percepción de aspectos de las condiciones de trabajo y la atribución de significados al trabajo por parte de empleados con puestos fijos de una empresa de construcción de edificios, con adopción 
extensiva de subcontratación (EA), con los de otra empresa con menos adopción de subcontratación (EB). En el estudio de campo, aplicamos, a 187 obreros, partes del Inventario de Significado del Trabajo y del Cuestionario de Condiciones de Trabajo, y entrevistamos a 16 obreros y dirigentes para diferenciar los contextos organizacionales. Verificamos, entre otros aspectos, que los empleados de la EB perciben más Riesgos de Accidentes Laborales y más Autonomía (jornada de trabajo y elección de colegas), mientras que los de la EA tienden a valorar más la Expresión de Respeto y Aceptación y atribuir más fuertes significados de Ser Reconocido y Ser Retribuido Equitativamente. Concluimos que el estilo gerencial probablemente causa más impacto en tales contenidos simbólicos de los obreros con puestos fijos que la extensión de la subcontratación.

Palabras-clave:

Subcontratación; empresas líderes; investigación comparativa; construcciones.

A terceirização é uma tradição na construção civil (Costa \& Tomasi, 2014), assim como em outros setores da economia (Costa \& Tomasi, 2014; Davis-Blake \& Broschak, 2009; Franco \& Druck 2008; Marcelino \& Cavalcante, 2012), intensificada a partir da década de 1990. Os processos tradicionais consistiam na subcontratação de empreiteiras sem registros, conhecidos no país como "gatos" (Costa \& Tomasi, 2014). A terceirização expandiu-se sob a influência dos novos modelos japoneses de gestão, com demandas como a focalização nos objetivos organizacionais, na competitividade e na redução de custos (Davis-Blake \& Broschak, 2009; Franco \& Druck, 2008; Marcelino \& Cavalcante, 2012).

Marcelino e Cavalcante (2012) consideraram consensual na literatura especializada que a extensão do fenômeno tenha modificado a estrutura da base produtiva e de serviços no país, afetando as relações trabalhistas e o bem-estar do trabalhador (Franco \& Druck, 2008; Franco, Druck, \& Seligmann-Silva, 2010; Grusenmeyer, 2014). Foi compreendido como meio de flexibilização e enxugamento das estruturas organizacionais (Costa \& Tomasi, 2014; Okamoto, Salermo, \& Melhado, 2014; Piccinini, Oliveira, \& Rübenich, 2006) e, ao mesmo tempo, como precarização das condições de trabalho, aprofundando a segmentação do mercado de trabalho, a desfiliação social e a fragmentação sindical (Azevedo, 2014; Franco \& Druck, 2008; Piccinini et al., 2006; Ponte, 2005; Russo \& Leitão, 2006).

A atenção acadêmica ao assunto, concomitantemente, se ampliou e revisões de literatura foram produzidas (p. ex., Davis-Blake \& Broschak, 2009; Marcelino \& Cavalcante, 2012). Davis-Blake e Broschack defenderam a tese de que a terceirização demanda mudanças na natureza do trabalho, na distribuição de atribuições e nas responsabilidades de supervisão, afetando os trabalhadores das empresas líderes em suas competências, bem como a sociabilidade no ambiente de trabalho. Em apoio, Grusenmeyer (2014), pesquisando sobre operadores de manutenção em empresa francesa de transporte, encontrou que a terceirização afetou os trabalhadores externos, como também o trabalho, a segurança e a saúde dos efetivos. Davis-Blake e Broschack (2009) constataram ainda que a maioria dos estudos abordou empresas fornecedoras de mão de obra, produtos e serviços.

Por essas razões, este estudo compara duas construtoras, líderes no papel exercido no processo de terceirização, e que diferem entre si pela extensão em que o adotam. A comparação focalizará, então, conteúdos simbólicos relativos à sociabilidade operária, coadunando-se com a necessidade de focalizar a cultura, como Davis-Blake e Broschack (2009) também assinalaram. Assim, relacionaremos a percepção de componentes das condições de trabalho e dos significados atribuídos pelos operários das duas empresas.

\section{Terceirização: Conceitos norteadores}

Não há conceito consensual sobre terceirização, mas dificuldades em caracterizá-la (Marcelino \& Cavalcante, 2012). Para Davis-Blake e Broschack (2009), o processo envolve a decisão de que a produção de bens e serviços será realizada fora da empresa, embora seja possível ser feita por seus próprios funcionários, e o definem como: “(...) obtenção de bens e serviços (...) de uma entidade externa, envolvendo algum tipo de relacionamento entre empresas (a empresa líder que adquire os bens ou serviços e a empresa parceira ou fornecedores que os cria)" (Davis-Blake \& Broschack, 2009, p. 323).

Notamos que esse conceito pressupõe a externalização das atividades e, portanto, exclui os processos em que os empregados da empresa fornecedora atuam dentro dos espaços da empresa líder e convivem com os funcionários efetivos, embora os referidos autores, ao avançarem em sua exposição, tenham descrito também a diversidade de tipos de contrato entre as empresas. Estes variam em formalidade, controle produtivo 
e envolvimento, bem como há possibilidades na dimensão do controle produtivo. Os autores identificaram alternativas em que empregados das empresas líderes e das fornecedoras formam uma rede.

Brandli, Martignag, Heineck, \& Cunha (1997), que se detiveram sobre o processo há mais tempo, diferenciaram terceirização e subcontratação, em que o primeiro processo se aplicaria às atividades-meio e o segundo às atividades-fim - com dois desdobramentos: um voltado para a execução de atividades específicas, geralmente usando tecnologias especializadas, e outro de subempreiteiras de mão de obra. Consideramos que o que foi excluído no primeiro conceito poderia ser apreendido pelo conceito de subcontratação.

Marcelino e Cavalcante (2012), porém, argumentaram que o termo terceirização é um neologismo brasileiro, criado em 1970 pelo engenheiro Aldo Sani, diretor-superintendente da Riocell, e que o termo em inglês poderia ser mais bem traduzido por subcontratação. A maioria dos textos (p. ex., Costa \& Tomasi, 2014; Ponte, 2005; Okamoto et al., 2014) escritos em nosso idioma tem utilizado os dois termos de maneira intercambiável. De qualquer forma, Marcelino e Cavalcante (2012) consideraram que a terceirização é apenas uma das formas de subcontratação. Identificaram que, na prática, convivem dois modelos: um, mais bem enquadrado no contexto da globalização e da reestruturação produtiva, que se orienta pelos objetivos de modernizar, flexibilizar e especializar (modelo ganha-ganha); e outro, que visa reduzir custos e externalizar responsabilidades trabalhistas (subcontratação por contingência). Admitiram, no entanto, fundamentados em outros autores (p. ex., Druck, 1995; Ponte, 2005), que os modelos são inseparáveis e o segundo predomina no Brasil.

Marcelino e Cavalcante (2012) optaram, então, por um conceito segundo o qual "terceirização é todo processo de contratação de trabalhadores por empresa interposta, cujo objetivo último é a redução de custos com a força de trabalho e/ou a externalização dos conflitos trabalhistas" (p. 338). Esses autores mostraram que as empresas líderes contratam diferentes tipos de fornecedores: (a) cooperativas de trabalhadores, (b) empresas em redes de fornecedores, (c) empresas subcontratadas para executarem atividades específicas, (d) prestadoras de serviços, (e) personalidades jurídicas (empresas com uma única pessoa ou empreendimentos sem empregados) e (f) terceirização delegada ou quarteirização.

Tal concepção de terceirização guiou nossa pesquisa e usaremos o termo sem nos preocuparmos em diferenciá-lo de subcontratação. Brandli et al. (1997), Costa e Tomasi (2014), Okamoto et al. (2014), focalizando o setor da construção civil, não só se referiram à frequência do uso da terceirização, como também a todos os tipos de fornecedores citados por Marcelino e Cavalcante (2012), exceto cooperativas de trabalhadores. Além disso, Costa e Tomasi (2014), em estudo de caso, descreveram o uso da terceirização como meio de apoiar um programa de racionalização do trabalho, facilitando lidar com a necessidade de contar com execução de atividades temporárias, devido ao dinamismo do ciclo de etapas da obra e/ou como estratégia para minimizar a rotatividade do pessoal efetivo. Essas terceirizações diferem de subcontratações tradicionais pelos cuidados legais, mas os autores descrevem que a empresa líder faz "vista grossa" (p. 349) para os direitos trabalhistas negados pelas terceirizadas e/ou empreiteiras. Okamoto et al. (2014) apontaram dificuldades de articular a rede de fornecedores, terceirizados e/ou subcontratados, e defenderam a importância da atividade de coordenação de projetos para os edifícios.

\section{Percepção das condições de trabalho}

No grupo de pesquisa em que estamos inseridos, abordamos as condições de trabalho englobando aspectos do entorno e o conteúdo do trabalho (Pietro, 1994, 2009). E adotamos, mais especificamente, o conceito de Ramos, Peiró e Ripoll (2002) de que as condições de trabalho consistem no conjunto dos aspectos circunstanciais em que se produzem as atividades de trabalho, considerando os fatores do entorno físico, as circunstâncias temporais e as condições em que os trabalhadores desempenham o trabalho.

Tal conceito pressupõe a multidimensionalidade do fenômeno e associa-se ao surgimento de tipologias (p. ex., Álvaro \& Garrido, 2005; Blanch, 2003; Ramos et al., 2002). Em nosso grupo de pesquisa, essas tipologias foram sintetizadas em quatro categorias (Tabela 1). Por uma questão de atenção aos aspectos simbólicos, não estudamos tais condições de trabalho por sua medição direta, mas a partir do olhar operário. O pressuposto é que tais condições afetarão a produção e as atitudes do trabalhador de acordo com sua percepção e avaliação. 
TABELA 1. As grandes categorias das condições de trabalho (taxonomia)

1) Condições contratuais e jurídicas

2) Condições físicas e materiais

3) Processos e características da atividade

4) Condições do ambiente sociogerencial

Referem-se ao conjunto de aspectos jurídicos (autônomo versus emprego), contratuais no caso do emprego (formal ou informal), de estabilidade do contrato (instável ou estável) e às modalidades de contrato formal (temporário, por tempo indefinido). Abrange ainda aspectos como o sistema de incentivo (retribuições) e as definições do tempo a ser dedicado ao trabalho.

São os componentes mais concretos. Referem-se ao entorno das atividades de trabalho no que diz respeito às condições físicas, o espaço arquitetônico e instalações, às condições de segurança física e/ou material e às formas em que se lida com o impacto do espaço geográfico e condições climáticas sobre o trabalho.

Abrange os aspectos que dizem respeito ao conteúdo das atividades de trabalho, à organização e divisão do trabalho, às demandas do posto de trabalho, aos modos de execução das atividades e ao desempenho do trabalhador.

Diz respeito aos aspectos relacionados às interações interpessoais (sejam horizontais, sejam verticais), às práticas sociais relativas à gerência, ou gestão, quando se trata do trabalho na forma de emprego (pois as condições de trabalho adquirem uma dimensão organizacional), e às práticas sociais decorrentes da inserção no mercado de trabalho (parcerias, redes de trabalho formais ou informais, etc.).

Nota. Fonte: Borges, Rocha-Falcão, Alves Filho e Costa (2015).

Desde Marx e Engels (1933/1981), as condições de trabalho são consideradas sócio-históricas, de modo que a noção de boas condições de trabalho varia segundo o desenvolvimento dos modos de produção de cada sociedade. Assim, em relação às condições de trabalho, diversos autores assinalaram a intensificação laboral (promovendo a precarização das condições de trabalho, sustentada pela insegurança do medo do desemprego) como um dos principais resultados da atual fase do capitalismo, com severas consequências aos trabalhadores (Bentoncini, Pires, \& Scherer, 2011; Braga, Carvalho, \& Binder, 2010; Franco \& Druck, 2008; Franco et al., 2010; Grusenmeyer, 2014; Mauro, Paz, Mauro, Pinheiro, \& Silva, 2010; Milanés \& Bustamante, 2010; Nascimento-Sobrinho, Carvalho, Bonfim, Cirino, \& Ferreira, 2006; Prazeres \& Navarro, 2011; Schmoeller, Trindade, Neis, Gelbcke, \& Pires, 2011). Exemplificando, Nascimento-Sobrinho et al. (2006), em pesquisa sobre condições de trabalho e a ocorrência de distúrbio psíquico menor (DPM) em médicos em Salvador, encontraram elevação de prevalência de DPM associada com baixo controle do trabalho e com alta demanda psicológica da atividade (relacionada ao volume excessivo de trabalho, ao tempo insuficiente para as tarefas, ao ritmo acelerado, às demandas conflitantes feitas por outras pessoas, à exigência de esforço físico e à interrupção das tarefas). Compreendemos, assim, que a percepção dos operários da construção de edificações concernente às condições de trabalho reflete a inserção social desses trabalhadores. Então, é esse conteúdo simbólico, carregado de conteúdo histórico e/ou das condições de vida contemporânea, que queremos discutir.

Retomando as categorias da Tabela 1, esclarecemos que cada uma abrange alguns indicadores (Borges et al., 2015), como possibilidade de controle do ritmo de trabalho, necessidade de cumprir prazos, monotonia e riscos gerados pelo uso de máquinas, entre outros. Borges et al. (2013) estudaram aqueles relativos às três últimas categorias, explorando sua estrutura fatorial para operários da construção de edificações e resultando na identificação de 20 fatores. Consideramos dois fatores relativos às condições físicas e materiais de trabalho - Falta de Segurança (perceber-se exposto a acidentes com ferramentas, instrumentos e maquinário, riscos de pequenos acidentes de trabalho e à falta de higiene no local de trabalho) e Riscos de Acidentes de Trabalho (perceber-se exposto a riscos de acidentes incapacitantes, fatais ou de pequena gravidade) -, e três fatores concernentes aos processos e às características da atividade - Rapidez e Complexidade (quanto o trabalho implica prazos rígidos e curtos, ritmo acelerado, tarefas monótonas e complexas, interrupção de uma tarefa por outras, problemas imprevistos; consecução de metas de produção e controle do chefe), Autonomia (quanto o trabalhador se percebe livre para negociar com chefes e colegas período de férias ou dias de folga, para influenciar sobre a escolha de seus colegas de trabalho e para fazer pausa e receber ajuda de seus superiores) e Definição de Atividades (quanto percebe suas tarefas sendo definidas pela equipe de trabalho, pelo chefe após ouvir a equipe ou pelo trabalhador sozinho, negociando com colegas e chefes).

Selecionamos tais fatores considerando a literatura revisada sobre terceirização. Franco e Druck (2008) apontaram que a terceirização suscita riscos e responsabilidades sobre a saúde e a segurança dos trabalhadores, promove a fragilização das condições de segurança, que, acrescidas à desestabilização dos "estáveis", podem impulsionar todos a se exporem a riscos para aumentar a produtividade. Ressaltaram, porém, a "invisibilidade" dos acidentes devido às subnotificações, principalmente entre trabalhadores terceirizados.

Rev. Psicol., Organ. Trab., abr-jun 2016, vol. 16 num 2 
Grusenmeyer (2014) observou que a intensificação da fragmentação e das interrupções na execução do trabalho, associadas à interdependência das atividades realizadas pelo pessoal interno e externo ou trabalhadores externos de diversas empresas, aumenta os riscos de acidentes. O Departamento Intersindical de Estatística e Estudos Socioeconômicos (DIEESE, 2014) registrou que os acidentes de trabalho são mais frequentes entre os terceirizados, especialmente nos setores da construção civil, de transportes de carga e de energia elétrica. Então, indagamos se tal realidade afeta a percepção dos efetivos sobre Falta de Segurança e Riscos de Acidentes.

Como mencionamos, Davis-Blake e Broschak (2009) e Grusenmeyer (2014) indicaram que a adoção da terceirização impacta a natureza do trabalho e a sociabilidade dos efetivos. Então, questionamos se tal impacto se expressa na percepção dos operários da construção de edificações em relação aos três fatores dos processos e características da atividade.

\section{Significados do trabalho}

Estudar os significados atribuídos pelas pessoas ao trabalho é considerar como elas se relacionam simbolicamente com o próprio trabalho e com a organização, quando é o caso. Autores como Berger e Luckmann (1985), Bruner (1990/1997) e Fiske (1992) defendem uma psicologia mais subjetiva, cultural e social para compreender os fenômenos em seus contextos. Bruner sustentou a tese de que os significados intermedeiam a relação do indivíduo com o mundo. Assim, os significados do trabalho medeiam nossa relação com o mundo do trabalho. Berger e Luckmann argumentaram que os significados são elaborados no processo de socialização que têm implicado o sujeito socializante e os demais agentes socializadores. Esses são atores significativos para o sujeito e para as instituições sociais, as quais contribuem para vincular cada um à sociedade e à cultura. Portanto, os significados são construídos nas experiências concretas de vida de cada sujeito.

Desse modo, adotamos o conceito de significados do trabalho segundo o qual esses são cognições subjetivas e sociais, que variam individualmente, na medida em que derivam do processo de atribuir significados e, simultaneamente, apresentam aspectos compartilhados e associados às condições históricas da sociedade (Borges \& Tamayo, 2001). Essa perspectiva de compreensão dos significados do trabalho é coerente às visões (p. ex., Morin, 2001; MOW, 1987) segundo as quais são complexos, dinâmicos, processuais e multifacetados, bem como à literatura (p. ex., Aktouf, 1986; Borges \& Barros, 2015; Martin-Baró, 1990), que tem assinalado que os significados do trabalho encerram contradições internas, como dignificar e, ao mesmo tempo, humilhar; alegrar e explorar, entre outros.

Dessa forma, levantar os significados que podem ser atribuídos ao trabalho é uma atividade extensa pela própria natureza do fenômeno. Além disso, diferentes autores têm norteado suas pesquisas por distintas dimensões do significado do trabalho (Bendassolli, 2011; Bendassolli \& Borges-Andrade, 2011; Kubo \& Gouvêa, 2012; Kubo, Gouvêa, \& Mantovani, 2013; Oliveira \& Silveira, 2012; Palassi \& Silva, 2014). Bendassolli e Borges-Andrade (2011) constataram que atividades com características artesanais e criativas podem preservar valores divergentes aos da ética atual de mercado.

Entre as dimensões focalizadas pelos autores do conceito adotado (Borges \& Tamayo, 2001), estão os atributos valorativos, que são crenças acerca de como o trabalho deve ser, e os descritivos, que se referem à apreensão de características concretas do trabalho. Considerando a indagação sobre o impacto da adoção da terceirização sobre os efetivos com relação às expectativas de sociabilidade (Davis-Blake \& Broschak, 2009; Grusenmeyer, 2014), escolhemos, a partir dos atributos valorativos, o significado de Expressão de Respeito e Acolhimento, que consiste em crenças de que o trabalho deve promover um ambiente de confiança e respeito, em que o trabalhador se sinta valorizado.

Estudos anteriores sobre os significados do trabalho para operários da construção de edificações exploraram, ora por meio da aplicação de análise fatorial (ver Borges \& Tamayo, 2001), ora por meio da aplicação da Smallest Space Analysis (ver Borges \& Barros, 2015), a estrutura cognitiva dos atributos valorativos. A reflexão sobre os tipos encontrados aponta que o tipo Expressão de Respeito e Acolhimento é aquele com conteúdos (itens) que podem ser compreendidos, abarcando expectativas de sociabilidade de maneira mais direta.

Considerando que a terceirização implica o convívio entre indivíduos de diferentes vínculos empregatícios, escolhemos, dos atributos descritivos, dois significados específicos: Ser Reconhecido (identificar o trabalho como algo importante para a sociedade e, ao mesmo tempo, como espaço de valorização da participação do trabalhador no processo produtivo), e Ser Retribuído Equitativamente (reconhecer o trabalho concreto como 
um dever de todos e um direito à retribuição proporcional ao empenho na execução das atividades). Esses tipos descritivos foram selecionados seguindo, portanto, os mesmos critérios dos atributos valorativos.

\section{MÉTODO}

Desenvolvemos as atividades de campo em duas empresas de construção e incorporação de edificações, atuantes na Região Metropolitana de Belo Horizonte (RMBH), sendo na Empresa A (EA) em janeiro de 2015 e na Empresa B (EB) em junho e julho de 2011. As duas organizações diferiam acentuadamente na extensão em que aplicavam a terceirização na execução das obras. Retomaremos tais diferenças na seção dos Resultados.

Desenvolvemos um estudo comparativo, contrapondo medidas de aspectos do significado do trabalho e da percepção das condições de trabalho entre os operários efetivos (diretamente contratados) das duas construtoras, a partir da aplicação de questionários estruturados (descritos adiante). Também foram realizadas entrevistas semiestruturadas para apreensão do contexto organizacional e da diferenciação das empresas.

\section{Participantes}

Da aplicação de questionários estruturados participaram 78 operários da EA e 109 da EB, incluídos na amostra pela acessibilidade e pela voluntariedade. A amostra era constituída, em sua maioria, por homens, sendo que da EB participaram 11 mulheres. Os operários da EA apresentaram tendência de terem mais idade $(M=39,81$ anos; $D P=12,36$ anos) do que os da $\mathrm{EB}(M=35,50$ anos; $D P=11,31$ anos), como o teste $t$ corroborou $(t=2,47 ; p=0,01)$.

Os participantes tinham, em média, 10,5 anos de trabalho no setor da construção civil e 2,8 anos na empresa atual. Não diferiram significativamente por empresas nesses aspectos (respectivamente: $t=-0,66$ para $p=0,51 ; t=-0,93$ para $p=0,35)$ e, em ambos os casos, a diferença entre os períodos reflete a rotatividade típica do setor. Foi predominante um nível de instrução de, no máximo, ensino fundamental completo $(74,4 \%$ na EA e $60,5 \%$ na EB), havendo tendência de instrução mais baixa na $\mathrm{EA}\left(\chi^{2}=3,38 ; p=0,05\right)$.

Além da amostra descrita, entrevistamos na EA seis operários e cinco técnicos e dirigentes (p. ex., engenheiros e mestres) e, na EB, três operários e três técnicos e dirigentes. A acessibilidade dos participantes diante das características do trabalho no setor econômico (p. ex., ritmo, continuidade das tarefas, relações hierárquicas, prazos) determinou o número de entrevistas.

\section{Instrumentos}

Aplicamos parte do Questionário de Condições de Trabalho - QCT (Borges et al., 2013) e do Inventário do Significado do Trabalho - IST (Borges \& Barros, 2015), além de uma ficha demográfica (p. ex., idade e instrução). Do QCT (Borges et al., 2013), utilizamos apenas 27 itens, respondidos segundo escala de frequência de 1 (nunca) a 5 (sempre). Do IST (Borges \& Barros, 2015), utilizamos 30 itens, respondidos em uma escala de 0 a 4 (Tabela 2).

TABELA 2. Componentes dos significados do trabalho e da percepção das condições de trabalho

\begin{tabular}{|c|c|c|}
\hline Componentes/exemplos de itens & $\begin{array}{l}\text { Número de } \\
\text { itens }\end{array}$ & $\begin{array}{l}\text { Alfa } \\
(\alpha)^{*}\end{array}$ \\
\hline \multicolumn{3}{|l|}{ Fatores das condições físicas e materiais de trabalho } \\
\hline $\begin{array}{l}\text { Falta de Segurança } \\
\text { Exemplos: "Quanto você se expõe às condições de trabalho abaixo? (...) Acidentes com ferramentas, instru- } \\
\text { mentos e maquinários (...) Situações que podem desenvolver doenças ocupacionais". }\end{array}$ & 5 itens & 0,75 \\
\hline $\begin{array}{l}\text { Riscos de Acidente de Trabalho. } \\
\text { Exemplos: "Quanto você se expõe às condições de trabalho abaixo? (...) Riscos de acidentes de trabalho inca- } \\
\text { pacitantes (...) Riscos de acidentes de trabalho fatais". }\end{array}$ & 4 itens & 0,76 \\
\hline \multicolumn{3}{|l|}{ Fatores das condições de trabalho referentes aos processos e características das atividades } \\
\hline $\begin{array}{l}\text { Rapidez e Complexidade } \\
\text { Exemplos: "O seu trabalho implica ritmo acelerado"; "De uma maneira geral, o seu ritmo de trabalho depende } \\
\text { do controle direto do seu chefe"; "O seu trabalho lhe exige realizar tarefas complexas". }\end{array}$ & 9 itens & 0,75 \\
\hline $\begin{array}{l}\text { Autonomia (jornada e escolha de colegas de trabalho) } \\
\text { Exemplos: "Você pode negociar com chefes e colegas quando tirar férias e/ou dias de folga?"; "Você tem influ- } \\
\text { ência sobre a escolha dos seus colegas de trabalho". }\end{array}$ & 5 itens & 0,56 \\
\hline $\begin{array}{l}\text { Definição de Atividades } \\
\text { Exemplos: "O que você faz é definido pela equipe de trabalho"; "O horário de seu trabalho é alterado com fre- } \\
\text { quência pela chefia sem aviso prévio a você". }\end{array}$ & 4 itens & 0,56 \\
\hline
\end{tabular}


Tipo valorativo dos significados do trabalho

Expressão de Respeito e Acolhimento

Exemplos: "Os chefes sabem como se comunicar com cada um"; "Os colegas me querem bem"; "Recebo toda 16 itens assistência que mereço".

Tipo descritivo dos significados do trabalho

Ser Reconhecido.

Exemplos: "As pessoas sabem quanto é importante o meu trabalho"; "Minhas opiniões sobre o trabalho são 8 itens

levadas em conta".

Ser Retribuído Equitativamente

Exemplos: "Trabalhar é obrigação de todas as pessoas"; "O que ganho no meu trabalho é suficiente e de acordo 6 itens com meu esforço"; "Todos os trabalhadores se esforçam como eu".

Nota. *Alfa $(\alpha)=$ Coeficiente alfa de Cronbach

Ambos os questionários (QCT e IST) já tiveram suas evidências de validade de construto e de consistência examinadas. Borges et al. (2013) submeteram o QCT à análise fatorial exploratória e a estimativa dos coeficientes alfa de Cronbach. Na última avaliação do IST, Borges e Barros (2015) aplicaram SSA (smallest space analysis), técnica recomendável para tratamento de conjunto de itens mais correlacionados. Estimaram também os coeficientes alfa de Cronbach (Tabela 2) para cada tipo valorativo e descritivo encontrado.

O roteiro de entrevistas abrangeu indagações sobre o estilo gerencial da empresa, seu sucesso e sua inserção no mercado de edificações e no cenário econômico, associando esses aspectos às condições e significados do trabalho.

\section{Procedimentos de coleta e análise de dados}

Iniciamos as atividades de campo após a autorização da pesquisa pelos dirigentes das empresas. Os questionários foram aplicados individualmente, preservando o anonimato dos participantes, com os Termos de Consentimento Livre e Esclarecido (TCLEs) guardados em envelope único, sem vinculá-los aos questionários. As questões foram lidas e as respostas registradas em dispositivo informatizado de mão, tipo Pocket PC. Utilizamos também fichas, representando as escalas de cada questionário por meio de tonalidades das cores e de números, dispensando a necessidade de o participante memorizar a escala (Borges et al., 2013; Borges \& Barros, 2015).

Transferimos as respostas gravadas no Pocket PC para o banco de dados do SPSS (Statistical Package of Social Science). Desenvolvemos as estatísticas exploratórias e aplicamos as demais análises estatísticas (estatísticas descritivas, testes t e análises de regressão), conforme apresentaremos na seção dos Resultados.

As entrevistas individuais também foram realizadas após aplicação de TCLE, gravadas com o consentimento do participante, tendo em vista a fluidez da entrevista e sua transcrição literal. Analisamos as entrevistas considerando os objetivos de sua aplicação e sistematizando as informações a partir da reflexão sobre o sentido das respostas.

\section{RESULTADOS}

\section{Do contexto e da diferenciação das empresas}

A sistematização das informações das entrevistas permitiu diferenciar as duas empresas (Tabela 3). Elas viviam diferentes cenários econômicos, mas ambas mantinham ações voltadas para a modernização da gestão e melhoria da qualidade dos serviços. Entrevistados da EA indicaram a validade dessas ações, referindo-se a reputação da empresa no mercado com afirmações como: "É tanto que hoje a [nome da empresa] quando chega a lançar um empreendimento na planta, ela vende em torno de $90 \%$ das suas unidades".

Ambas contavam com órgãos centralizados de desenvolvimento de recursos humanos, entretanto, com focos distintos: um em benefícios, e outro, em apoio à produção. Por consequência, um operário entrevistado considerou a concessão de benefícios da EB seu diferencial. Em contrapartida, outro se referiu ao ritmo do trabalho como o aspecto mais incômodo na empresa, provavelmente por estar relacionado à política salarial, bastante distinta entre as duas empresas (Tabela 3). 


\begin{tabular}{|c|c|}
\hline Empresa A & Empresa B \\
\hline \multicolumn{2}{|c|}{ Cenário econômico } \\
\hline $\begin{array}{l}\text { - Conjuntura de incerteza, com várias empresas em dificuldades } \\
\text { econômicas. }\end{array}$ & - "Boom" da construção civil/edificações. \\
\hline \multicolumn{2}{|c|}{ Gestão } \\
\hline $\begin{array}{l}\text { - Mais proximidade entre a direção centralizada e os canteiros de } \\
\text { obras e entre os níveis hierárquicos dentro do canteiro. } \\
\text { - Órgão de recursos humanos mais focalizado na produtividade. }\end{array}$ & $\begin{array}{l}\text { - Mais distanciamento entre os níveis hierárquicos. } \\
\text { - Órgão de recursos humanos forte no tocante aos benefícios so- } \\
\text { ciais. }\end{array}$ \\
\hline \multicolumn{2}{|c|}{ Políticas salariais e de benefícios para empregados efetivos } \\
\hline $\begin{array}{l}\text { - Pagamento de salário fixo conforme contrato e Acordo Coletivo. } \\
\text { - Benefícios praticamente restritos às exigências legais. } \\
\text { - Políticas mais estritas de concessão de horas-extraordinárias }\end{array}$ & $\begin{array}{l}\text { - Pagamento de salário fixo e parte variável (adicionais vinculados à } \\
\text { consecução de metas de produção por equipe). } \\
\text { - Sorteio de eletrodomésticos, para os quais concorriam os empre- } \\
\text { gados com assiduidade integral. } \\
\text { - Leque um pouco mais amplo de benefícios sociais. }\end{array}$ \\
\hline & irização \\
\hline
\end{tabular}

- Aproximadamente $2 / 3$ de cada canteiro.

- Variedade de tipo de contratadas incluindo personalidade jurí- - Aproximadamente $10 \%$ de cada canteiro. dica.

- Dispunham de técnicos de segurança, mas canteiros próximos

compartilhavam o mesmo técnico.

\section{Segurança} sobre os acidentes ocorridos.

\section{Sociabilidade e atividades}

- Dificuldade em formar equipes.

- Trabalhadores efetivos executando "acertos" do que havia sido realizado pelos terceirizados.

- Terceirizados em atividades pontuais e especializadas.

- Relatos de entrosamento de qualidade entre os efetivos e intera-

Poucas menções aos terceirizados.

ções amistosas e abertas entre os níveis hierárquicos.

A diferença de extensão da adoção da terceirização era muito acentuada entre as duas empresas. Nas entrevistas da EA, a estratégia da terceirização apareceu como um meio de contratar pessoal em quantidade suficiente para executar as etapas da obra, cumprindo os prazos estabelecidos, bem como de externalizar despesas oriundas da rotatividade. Há menções de que os operários das terceirizadas ganham mais e trabalham mais. Os dirigentes falaram na terceirização como a saída para manter a viabilidade econômica das obras e, ao mesmo tempo, assinalaram problemas como: a formação descontínua da equipe, o aumento do esforço em treinar os novatos e o descumprimento de direitos trabalhistas por parte das empresas contratadas, a despeito do contrato firmado com a empresa líder.

Os relatos também indicaram despreparo e improvisação das contratadas, que terminam exigindo dos empregados efetivos, técnicos e dirigentes, que atuassem como "consultores" das empreiteiras, ensinando como deveriam trabalhar; além de impactar na sintonização das funções da empresa líder (p. ex., funções de compra de materiais e manutenção de estoque) e nas etapas da obra. Além disso, exigem também um acompanhamento contínuo dos operários, mesmo intermediado pelo empreiteiro, que deve estar sempre na obra. Parte do trabalho dos operários efetivos consiste em fazer "acertos" das tarefas executadas pelas terceirizadas.

Em relação à sociabilidade, apesar das diferenças entre as empresas, mencionaram um ambiente amistoso entre os efetivos, sendo que na EA um operário afirmou que o clima de amizade lhe mantinha na empresa.

\section{Resultados dos questionários estruturados}

Estimamos as médias e os desvios-padrão nos fatores da percepção das condições de trabalho e nos componentes dos significados do trabalho dos operários participantes da pesquisa, segundo a empresa empregadora, e aplicamos o teste $t$ (Tabela 4). Os resultados mostraram predomínio de diferenças estatisticamente significativas ( $p \leq 0,05)$, com exceção dos fatores Falta de Segurança (dimensão das condições físicas e materiais) e Definição das Atividades (dimensão dos processos e características das atividades) da percepção das condições do trabalho.

Em relação aos aspectos em que o teste $t$ indicou haver diferença significativa, constatamos a tendência dos empregados efetivos da EB perceberem mais Riscos de Acidentes de Trabalho e mais Autonomia (jornada de trabalho e escolha de colegas), enquanto os da EA tendem a valorizar mais a Expressão de Respeito e Acolhimento e atribuírem mais fortemente significados de Ser Reconhecido e Ser Retribuído Equitativamente. 
TABELA 4. Médias, desvios-padrão nos componentes da percepção de condições de trabalho e dos significados do trabalho e coeficientes do teste $t$

\begin{tabular}{|c|c|c|c|c|}
\hline Componentes & Empresas & M & DP & Teste t \\
\hline \multicolumn{5}{|c|}{ Fatores das condições físicas e materiais de trabalho } \\
\hline \multirow{2}{*}{ Falta de Segurança } & EA & 2,95 & 0,86 & \multirow{2}{*}{$t=-0,07 ; p=0,95$} \\
\hline & EB & 2,94 & 1,12 & \\
\hline \multirow{2}{*}{ Riscos de Acidentes de Trabalho } & EA & 2,65 & 1,06 & \multirow{2}{*}{$t=2,00 ; p=0,05$} \\
\hline & EB & 2,98 & 1,12 & \\
\hline \multicolumn{5}{|c|}{ Fatores das condições de trabalho referentes aos processos e características das atividades } \\
\hline \multirow{2}{*}{ Rapidez e Complexidade } & EA & 2,92 & 0,88 & \multirow{2}{*}{$t=3,11 ; p=0,002$} \\
\hline & EB & 3,31 & 0,82 & \\
\hline \multirow{2}{*}{ Autonomia (jornada e escolha de colegas) } & EA & 2,07 & 0,78 & \multirow{2}{*}{$t=3,67 ; p<0,001$} \\
\hline & EB & 2,52 & 0,85 & \\
\hline \multirow{2}{*}{ Definição das Atividades } & EA & 3,21 & 0,93 & \multirow{2}{*}{$t=1,84 ; p=0,07$} \\
\hline & EB & 3,45 & 0,87 & \\
\hline \multicolumn{5}{|c|}{ Tipo valorativo dos significados do trabalho } \\
\hline \multirow{2}{*}{ Expressão de Respeito e Acolhimento } & EA & 4,66 & 0,31 & \multirow{2}{*}{$t=-19,75 ; p<0,001$} \\
\hline & EB & 3,83 & 0,26 & \\
\hline \multicolumn{5}{|c|}{ Tipo descritivo dos significados do trabalho } \\
\hline \multirow{2}{*}{ Ser Reconhecido } & EA & 3,55 & 0,76 & \multirow{2}{*}{$t=-9,50 ; p=0,001$} \\
\hline & EB & 2,49 & 0,76 & \\
\hline \multirow{2}{*}{ Ser Retribuído Equitativamente } & EA & 3,63 & 0,72 & \multirow{2}{*}{$t=-13,66 ; p=0,001$} \\
\hline & EB & 2,15 & 0,74 & \\
\hline
\end{tabular}

Considerando que a descrição da amostra revelou que os empregados das duas empresas se diferenciavam de forma significativa pela idade e pela instrução, examinamos as correlações entre idade e os componentes de condições de trabalho e do significado do trabalho. Encontramos que a idade se correlacionou significativamente com os tipos descritivos Ser Reconhecido $(r=0,21 ; p=0,04)$ e Ser Retribuído Equitativamente $(r=0,23$; $p=0,02)$. Os escores em cada componente foram comparados segundo quem havia estudado até o ensino fundamental completo e quem tinha mais instrução que esse nível de ensino. O nível de instrução (dicotômico) conseguiu diferenciar os escores nos mesmos componentes (respectivamente $t=2,72$ para $p=0,007$ e $t=2,43$ para $p=0,01)$. Então, para distinguir o impacto dessas variáveis sociodemográficas e o da própria organização, desenvolvemos análise de regressão múltipla hierárquica (stepwise), tomando os dois componentes (um de cada vez) como variável critério e a idade, o nível de instrução (dicotômico) e a organização (se empregado em EA ou EB) como variáveis antecedentes.

Na primeira regressão, em que Ser Reconhecido é a variável critério (Tabela 5), apenas a empresa ofereceu predição estatisticamente significativa e explicou 33\% da variância. Na segunda regressão, em que Ser Retribuído Equitativamente é a variável critério (Tabela 5), além da empresa, a idade também ofereceu predição estatisticamente significativa, entretanto, dos $51 \%$ da explicação da variância obtida, a idade contribuiu apenas com $1 \%$.

TABELA 5. Análises de regressão

\begin{tabular}{|c|c|c|c|c|c|c|}
\hline & \multirow[t]{2}{*}{ Modelo } & $\begin{array}{c}\text { Coeficientes não } \\
\text { padronizados }\end{array}$ & $\begin{array}{l}\text { Coeficientes } \\
\text { padronizados }\end{array}$ & \multirow[t]{2}{*}{$t$} & \multirow{2}{*}{$\begin{array}{c}\text { Nível de } \\
\text { significância }\end{array}$} & \multirow{2}{*}{$\begin{array}{c}\begin{array}{c}\text { Proporção de } \\
\text { explicação }\end{array} \\
R^{2}\end{array}$} \\
\hline & & $B$ & $\beta$ & & & \\
\hline \multicolumn{7}{|c|}{ Ser Reconhecido como variável dependente } \\
\hline \multirow{2}{*}{1} & (Constante) & 0,35 & & 1,26 & 0,209 & \multirow{2}{*}{0,33} \\
\hline & Empresa & 1,07 & 0,57 & 9,51 & 0,000 & \\
\hline \multicolumn{7}{|c|}{ Ser Retribuído Equitativamente como variável dependente } \\
\hline \multirow{3}{*}{1} & (Constante) & $-0,82$ & & $-3,05$ & 0,003 & \multirow{3}{*}{0,50} \\
\hline & Empresa & 1,48 & 0,71 & 13,66 & 0,000 & \\
\hline & (Constante) & $-1,06$ & & $-3,62$ & 0,000 & \\
\hline \multirow[t]{2}{*}{2} & Empresa & 1,44 & 0,69 & 13,19 & 0,000 & \multirow[t]{2}{*}{0,51} \\
\hline & Idade & 0,01 & 0,10 & 1,98 & 0,049 & \\
\hline
\end{tabular}

Com o intuito de compreender quais aspectos das organizações estavam contribuindo para a explicação da variância de tais componentes dos significados do trabalho, repetimos as regressões adicionando os fatores das condições de trabalho como o terceiro bloco de variáveis antecedentes. Em relação a Ser Reconhecido, o 
modelo final obtido passou a explicar $50,1 \%$ da variância, sendo então os preditores (variáveis antecedentes): empresa $(\beta=0,60)$; Rapidez e Complexidade $(\beta=-0,25)$; Autonomia $(\beta=0,23)$; Falta de Segurança $(\beta=-0,18)$; e Definição de Atividades $(\beta=0,13)$. O coeficiente beta de Rapidez e Complexidade e o de Falta de Segurança indicam uma relação inversamente proporcional à variável critério.

Em relação a Ser Retribuído Equitativamente, o mesmo procedimento resultou em um modelo final de regressão que explicou $58 \%$ da variância e tomou como preditores as seguintes variáveis antecedentes: empresa $(\beta=0,67)$; idade $(\beta=0,12)$; Riscos de Acidentes de Trabalho $(\beta=-0,16)$; Rapidez e Complexidade $(\beta=-0,14)$; e Autonomia $(\beta=0,12)$.

\section{DISCUSSÃO}

A descrição do contexto das empresas revelou que as comparações entre os conteúdos simbólicos referentes à percepção operária das condições de trabalho e os significados que atribuem ao trabalho têm por trás as diferenciações entre as empresas a que os participantes se vinculam. De um lado, há uma empresa marcada pela extensa terceirização, por um estilo de gestão em que há maior aproximação entre os níveis hierárquicos e que vive um período econômico de incertezas (EA); de outro, há uma empresa marcada pela aplicação de incentivos econômicos à produção e à assiduidade, vivendo um período de crescimento econômico.

A extensão da terceirização na conjuntura econômica atual, com os estilos gerenciais que emergiram nas entrevistas, corrobora a literatura consultada no sentido da inseparabilidade das finalidades de modernização, especialização e flexibilização, de um lado, e de redução de custos e externalização de obrigações trabalhistas, de outro (Costa \& Tomasi, 2014; Druck, 1995; Marcelino \& Cavalcante, 2012; Ponte, 2005). Apesar disso, reconhecemos que o segundo conjunto de objetivos se expressa mais no cotidiano do canteiro de obras. O impacto do despreparo de algumas empresas contratadas na harmonização de funções corrobora a tese de Okamoto et al. (2014) da necessidade de adoção de um trabalho de coordenação de projetos das subcontratadas na construção de edifícios. A sustentação do que encontramos sobre as características de terceirização da EA na literatura (p. ex., Costa \& Tomasi, 2014; Druck, 1995; Marcelino \& Cavalcante, 2012; Ponte, 2005) indica que seja um caso com semelhanças a empresas que adotam tal estratégia na contemporaneidade e do setor específico da construção de edificações.

Compreendemos, então, as diferenças entre as empresas como fonte de reflexão e indagação sobre os resultados obtidos dos questionários estruturados. Nosso objetivo consistiu em indagar sobre o impacto da terceirização em componentes da percepção das condições de trabalho e dos significados do trabalho nos empregados efetivos, quando a empresa faz uso extensivo de terceirização. Os resultados encontrados (Tabela 3) mostraram que os escores não se diferenciam significativamente apenas em dois componentes das condições de trabalho - percepção de Falta de Segurança e de Definição de Atividades -, implicando responder negativa e parcialmente nossa questão acerca da percepção dos empregados efetivos sobre segurança e riscos de acidentes e negativamente a questão relativa ao impacto sobre a natureza do trabalho no que se refere à participação na Definição das Atividades.

Em relação à Falta de Segurança, os resultados contradizem parcialmente os argumentos de Franco e Druck (2008) e Grusenmeyer (2014). Em relação ao fator Definição das Atividades, os resultados aparentemente contradizem a tese de Marcelino e Cavalcante (2012) e de Grusenmeyer sobre o impacto na natureza do trabalho. Entretanto, assinalamos que Definição de Atividades é apenas um aspecto da natureza do trabalho. A não existência de diferença significativa, em contrapartida, assinala que em ambos os casos - gestão por metas e terceirização - está preservado o caráter das atividades construtivas em que as prescrições são parciais e há sempre espaço para realização das atividades segundo a experiência e autonomia do próprio operário (Costa \& Tomasi, 2014). De qualquer forma, não podemos deixar de sublinhar que o nível de significância do coeficiente $t$ foi de 0,07 , apenas um pouco maior que o limite adotado $(p \leq 0,05)$. Tal nível de significância pode ser tomado como uma sugestão para voltar a testá-lo em uma amostra maior.

As diferenças encontradas (nas demais medidas) no teste $t$ foram, entretanto, na maioria dos casos, na direção contrária do que esperávamos, a despeito da extensão da terceirização da EA. Compete-nos indagar, frente à diferenciação entre as empresas descritas na seção anterior, que razões sustentam tais resultados. Por que os empregados da EA percebem menos Riscos de Acidente de Trabalho que os da EB? Na EB, entrevistas associaram a aplicação das políticas salariais com adicionais por consecução de metas aos descasos no uso de EPI. Na EA, sendo os efetivos um contingente pequeno, devemos indagar se eles não estão ficando com 
as atividades menos arriscadas. Há o caso do operário que relatou fazer "acertos" nas atividades realizadas anteriormente pelos terceirizados.

Por que os empregados da EB percebem mais exigências de Rapidez e Complexidade? Provavelmente as políticas salariais e de benefícios, que são diferenciais da $\mathrm{EB}$, fazem seus empregados efetivos pontuarem mais nesse fator. A probabilidade das razões de tal pontuação estar nas características da empresa aumenta com o fato de não termos encontrado correlações dos escores do fator com aspectos da ficha demográfica.

No fator Autonomia (jornada e escolha de colegas), a diferença foi na direção esperada, pois os empregados da EA tiveram menor pontuação, corroborando o que esperávamos sobre empobrecimento da sociabilidade, devido à rotatividade e à instabilidade dos empregados terceirizados (Davis-Blake \& Bloschak, 2009; Grusenmeyer, 2014). Embora um operário entrevistado da EA tenha se referido ao clima amigável entre efetivos, os resultados corroboram a ideia de uma tendência a não estabelecer laços com os terceirizados. Isso também é corroborado pelos relatos de técnicos e dirigentes da EA sobre a dificuldade de formar equipes.

Por que os escores nos atributos valorativos dos significados do trabalho Expressão de Respeito e Acolhimento foram mais elevados para os empregados da EA? Provavelmente refletem a maior proximidade entre os níveis hierárquicos no contexto de uma empresa com um contingente pequeno de trabalhadores efetivos. Lembramos que esses escores também não se correlacionaram com as características demográficas, aumentando a probabilidade de nossa hipótese explicativa.

E finalmente nos perguntamos: por que os empregados da EA indicam que se sentem mais reconhecidos no trabalho do que os da EB? Pensamos que esse resultado poderia estar espelhando o perfil dos empregados, visto que os da EA tendiam a ter mais idade e menos instrução. Entretanto, testamos essa possibilidade por meio de análise de regressão (Tabela 5), rejeitando tal hipótese. Ao testar os fatores das condições de trabalho, estes oferecem predição aos escores de Ser Reconhecido, embora menos do que a variável empresa. E revela que os escores mais elevados de Rapidez e Complexidade na EB são concernentes a esperar menores escores na EB em Ser Reconhecido. Em compensação, os escores em Autonomia deveriam ajudar. A partir dessas observações, e sendo a empresa o melhor preditor dos escores de Ser Reconhecido, consideramos provável que os escores mais elevados da EA se associem parcialmente à maior horizontalidade nas relações interpessoais entre os níveis hierárquicos, à menor pressão por rapidez e complexidade e à conjuntura econômica de incerteza. Tal conjuntura, diminuindo as expectativas de crescimento profissional, poderia fazer as pessoas se sentirem reconhecidas por serem empregados efetivos.

Pontuar mais em Ser Retribuído Equitativamente tem influência da idade, porém, é muito menor do que a da empresa em que se trabalha (Tabela 5). No entanto, a regressão que incluiu como variáveis antecedentes fatores das condições de trabalho expõe que perceber menos Riscos de Acidentes de Trabalho e menos exigências de Rapidez e Complexidade influencia positivamente atribuir o significado de Ser Retribuído Equitativamente. O trabalhador realizar atividades que percebe como menos arriscadas e se sentir mais livre no ritmo em que trabalha certamente têm sentidos humanizantes que os tornam preditores de atribuir significados referentes a Ser Retribuído Equitativamente. No entanto, como o principal preditor segue sendo a empresa, levantamos também a hipótese de que a avaliação de equidade é influenciada pela conjuntura econômica de incerteza.

O conjunto dos resultados é um caso específico e pode não representar a totalidade do que ocorre na construção de edificações, de modo que em outras situações seja possível que os resultados se apresentem em direções diferentes. Entretanto, os resultados encontrados pontuaram que os impactos da terceirização extensiva sobre os empregados efetivos da empresa líder não independem das demais características da gestão e da organização do trabalho nas empresas, nem da conjuntura econômica.

Outra conclusão plausível seria a hipótese de que a terceirização não só externaliza encargos trabalhistas e de rotatividade, mas causa vários outros impactos na organização do trabalho. Será que os resultados encontrados para os empregados da EB, que são mais preocupantes, foram transferidos na EA para os terceirizados em vez de serem realmente superados? Nossa indagação leva em conta os achados da literatura sobre os impactos da terceirização sobre a saúde psíquica dos trabalhadores das empresas fornecedoras e/ou empreiteiras.

Os resultados encontrados fortalecem também a necessidade de que, para aprofundar a compreensão dos impactos da terceirização na sociabilidade e na natureza do trabalho, as seguintes questões devem ser consideradas: Quanto é exigido dos trabalhadores em relação a prazos e a resolução de problemas com poucos recursos? Quanto e como eles têm oportunidades de estabelecer laços e formarem equipes de trabalho? Quanto eles 
percebem respeito aos cuidados que devem tomar para garantir segurança? Que novas atribuições e encargos assumem as gerências médias e técnicos especializados?

Além disso, necessitamos registrar uma preocupação diante desses resultados: se é possível, nas organizações médias, neutralizar os impactos da terceirização para os empregados que se mantêm como efetivos, ou até torná-los positivos, como seguirá, em uma sociedade desigual, a atenção a ser dada aos impactos da terceirização sobre os empregados que passam a trabalhar nas empresas contratadas? Qual o compromisso ético dos efetivos em questionar e em transformar o trabalho para que todos tenham direito a um trabalho decente? Por fim, além de atingir o objetivo geral traçado inicialmente, que motivou o desenvolvimento da pesquisa, avaliamos que o caráter surpreendente da maioria dos resultados foi fértil para levantar questões para novos estudos.

\section{REFERÊNCIAS}

Aktouf, O. (1986). Une visíon interne des rapports de travail: Le cas de deux brasseries. Le travail humain, 49(3), 237-248.

Álvaro, J. L., \& Garrido, A. (2005). Trabajo, ocupación y bienestar. In A. Garrido (Org.), Sociopsicologia del trabajo (pp. 99-132). Barcelona: Editorial UOC.

Azevedo, F. C. (2014). Consultoria empresarial de serviço social: Expressões da precarização e da terceirização profissional. Serviço Social \& Sociedade, 118, 318-338. doi: 10.1590/S0101-66282014000200006

Bendassolli, P. F. (2011). Crítica às apropriações psicológicas do trabalho. Psicologia \& Sociedade, 23(1), 75-84. doi: /10.1590/ S0102-71822011000100009

Bendassolli, P. F., \& Borges-Andrade, J. E. (2011). Significado do trabalho nas indústrias criativas. Revista de Administração de Empresas, 51(2), 143-159. doi: 10.1590/S0034-75902011000200003

Bentoncini, J. H., Pires, D. E. P., \& Scherer, M. D. A. (2011). Condições de trabalho e renormalizações nas atividades das enfermeiras na saúde da família. Trabalho, Educação e Saúde, 9(S1), 157-173. doi: 10.1590/S1981-77462011000400008

Berger, P. L., \& Luckmann, T. (1985). A construção social da realidade. Petrópolis: Vozes.

Blanch, J. M. (2003). Condiciones de trabajo. In J. M. Blanch, M. J. Espuny, C. Gala \& A. Martín, Teoría de las relaciones laborales: Fundamentos (pp. 42-44). Barcelona: Editorial UOC.

Borges, L. O., \& Barros, S. C. (2015). Inventário de significado do trabalho. In K. Puente-Palacios \& A. L. A. Peixoto (Orgs.), Ferramentas de diagnóstico para organizações e trabalho: Um olhar a partir da psicologia (pp. 232-260). Porto Alegre: Artmed.

Borges, L. O., Pires, M. T., Alves Filho, A., Souza, A. L. R., Falcão, J. T., Leite, C. L. R. A., \& Barros, S. C. (2013). Questionário de condições de trabalho: Reelaboração e estruturas fatoriais em grupos ocupacionais. Avaliação Psicológica, 12(2), 213225.

Borges, L. O., Rocha-Falcão, J. T., Alves Filho, A., Costa, M. T. P. (2015). Condições de Trabalho. In P. F. Bendassolli, \& J. E. Borges-Andrade (Orgs.), Dicionário de psicologia do trabalho e das organizações (pp. 227-236). São Paulo: Casa do Psicólogo.

Borges, L. O., \& Tamayo, A. (2001). A estrutura cognitiva do significado do trabalho. Revista Psicologia: Organizações e Trabalho, 2(1), 11-44.

Braga, L. C., Carvalho, L. R., \& Binder, M. C. P. (2010). Condições de trabalho e transtornos mentais comuns em trabalhadores da rede básica de saúde de Botucatu (SP). Ciência \& Saúde Coletiva, 15(S1), 1585-1596. doi: 10.1590/S141381232010000700070

Brandli, L. L., Martignag, G., Heineck, L. F. M., \& Cunha, C. J. C. A. (1997, outubro). Estratégias de terceirização e subcontratação na construção civil. Anais do XVII Encontro Nacional de Engenharia de Produção e 3rd International Congress of Industrial Engineering. Porto Alegre: Universidade do Rio Grande do Sul. Recuperado de http://www.abepro. org.br/biblioteca/ENEGEP1997_T3203.PDF

Bruner, J. (1997). Actos de significado: Para uma psicologia cultural. (V. Prazeres, Trad.). Lisboa: Edições 70. (Obra original publicada em 1990).

Costa, L. R., \& Tomasi, A. P. N. (2014). De peão a colaborador: Racionalização e subcontratação na construção civil. Caderno CRH, 27(71), 347- 365. doi: 10.1590/S0103-49792014000200009

Davis-Blake, A., \& Broschak, J. P. (2009). Outsourcing and the changing nature of work. Annual Review of Sociology, 35, 321-40. doi: 10.1146/annurev.soc.34.040507.134641 
Departamento Intersindical de Estatística e Estudos Socioeconômicos. (2014). Terceirização e desenvolvimento: Uma conta que não fecha. Dossiê acerca do impacto da terceirização sobre os trabalhadores e propostas para garantir a igualdade de direitos. São Paulo: CUT. Recuperado de http://www.cut.org.br/system/uploads/ck/files/Dossie-Terceirizacao-eDesenvolvimento.pdf

Druck, M. G. (1995). Terceirizando: (Des)fordizando a fábrica. Um estudo do complexo petroquímico da Bahia (Tese de doutorado não publicada). Universidade Estadual de Campinas, Campinas.

Fiske, S. (1992). Thinking is for doing: Portraits of social cognition from daguerrreotype to laserphoto. Journal of Personality and Social Psychology, 63(6), 877-889.

Franco, T., \& Druck, G. (novembro, 2008). O trabalho contemporâneo: Precarização e saúde mental. In Seminário Nacional de Saúde Mental e Trabalho. São Paulo: Fundacentro. Recuperado de http://www.fundacentro.gov.br/Arquivos/sis/ EventoPortal/AnexoPalestraEvento/Mesa\%20redonda\%201\%20-\%20Trabalho\%20contempor\%C3\%A2neo.pdf

Franco, T., Druck, G., \& Seligmann-Silva, E. (2010). As novas relações de trabalho, o desgaste mental do trabalhador e os transtornos mentais no trabalho precarizado. Revista Brasileira de Saúde Ocupacional, 35(122), 229-248. doi: 10.1590/ S0303-76572010000200006

Grusenmeyer, C. (2014). Maintenance: Organizational modes, activities and health and safety. Use of a French national survey and in-situ analyses. Accident Analysis and Prevention, 73, 187-199. doi: 10.1016/j.aap.2014.09.009

Kubo, S. H., \& Gouvêa, M. A. (2012). Análise de fatores associados ao significado do trabalho. Revista de Administração, 47(4), 540-554. doi: 10.5700/rausp1057

Kubo, S. H., Gouvêa, M. A., \& Mantovani, D. M. N. (2013). Dimensões do significado do trabalho e suas relações. Pretexto, 14(3), 28-49.

Marcelino, P., \& Cavalcante, S. (2012). Por uma definição de terceirização. Cadernos CRH, 25(65), 331-346. doi: 10.1590/S010349792012000200010

Martin-Baró, I. (1990). ¿Trabajador alegre o trabajador explotado? La identidad del salvadoreño. Revista Interamericana de Psicologia, 24(1), 1-24.

Marx, K., \& Engels, F. (1981). A ideologia alemã. Lisboa: Editora Avante! (Obra original publicada em 1933).

Mauro, M. Y. C., Paz, A. F., Mauro, C. C. C., Pinheiro, M. A. S., \& Silva, V. G. (2010). Condições de trabalho da enfermagem nas enfermarias de um hospital universitário. Escola Anna Nery - Revista de Enfermagem, 14(1), 13-18. doi: 10.1590/S141481452010000200006

Milanés, Z. C., \& Bustamante, E. G. (2010). Condiciones laborales en enfermeras de cartagena, Colombia. Avances en Enfermería, 28(1), 31-38.

Morin, E. M. (2001). Os sentidos do trabalho. Revista de Administração de Empresas, 41(3), 08-19. doi: 10.1590/S003475902001000300002

Meaning of Work International Research Team (1987). The meaning of working. London: Academic Press.

Nascimento Sobrinho, C. L., Carvalho, F. M., Bonfim, T. A. S., Cirino, C. A. S., \& Ferreira, I. S. (2006). Condições de trabalho e saúde mental dos médicos de Salvador, Bahia, Brasil. Cadernos de Saúde Pública, 22(1), 131-140. doi: 10.1590/S0102$311 \times 2006000100014$

Okamoto, P. S., Salermo, M. S., \& Melhado, S. (2014). A coordenação de projetos subcontratados na construção civil. Gestão e Tecnologia de Projetos, 9(1), 123-142. doi: 10.11606/gtp.v9i1.68149

Oliveira, M. C. L., \& Silveira, S. B. (2012). O(s) sentido (s) do trabalho na contemporaneidade. Linguística Aplicada das Profissões, 16(1), 149-165. R

Palassi, M. P., \& Silva, A. R. L. (2014). A dinâmica do significado do trabalho na iminência de uma privatização. Revista de Ciências da Administração, 16(38), 47-62. doi: 10.5007/2175-8077.2014v16n38p47

Piccinini, V. C., Oliveira, S. R., \& Rübenich (2006). Formal, flexível ou informal? Reflexões sobre o trabalho no Brasil. In V. C. Piccinini, L. Holzmann, I. Kovács \& V. N. Guimarães (Orgs.), O mosaico do trabalho na sociedade contemporânea: Persistências e inovações (pp. 93-118). Porto Alegre: Editora da UFRGS.

Pietro, C. (1994). Trabajadores y condiciones de trabajo. Madri: Ediciones HOAC.

Pietro, C. (2009). La calidad del empleo en España: Una aproximación teórica y empírica. Madrid: Ministério de Trabajo e Inmigración.

Ponte, J. R. T. (2005). Terceirização - Uma abordagem crítica. In M. N. O. Araújo \& L. C. Rodrigues (Orgs.), Transformações no mundo do trabalho - Realidades e utopias (pp. 85-107). Fortaleza: Editora UFC. 
Prazeres, T. J., \& Navarro, V. L. (2011). Na costura do sapato, o desmanche das operárias: Estudo das condições de trabalho e saúde das pespontadeiras da indústria de calçados de Franca, São Paulo, Brasil. Cadernos de Saúde Pública, 27(10), 1930-1938. doi: 10.1590/S0102-311X2011001000006

Ramos, J., Peiró, J. M., \& Ripoll, P. (2002). Condiciones de trabajo y clima organizacional. In J. M. Peiró \& F. Prieto (Org.), Tratado de psicología del trabajo: La actividad laboral en su contexto (pp. 37-92). Madrid: Síntesis Psicología.

Russo, G. M., \& Leitão, S. P. (2006). Terceirização: Uma análise desconstrutivista. Organizações \& Sociedade, 13(36), 107-123. doi: 10.1590/S1984-92302006000100006

Schmoeller R., Trindade, L. L., Neis, M. B., Gelbcke, F. L., \& Pires, D. E. P. (2011). Cargas de trabalho e condições de trabalho da enfermagem: Revisão integrativa. Revista Gaúcha de Enfermagem, 32(2), 368-77. doi: 10.1590/S198314472011000200022 